\title{
Relationships Among Rheological and Sensorial Properties of Young Cheeses
}

\author{
J. A. Brown, ${ }^{\star}$ E. A. Foegeding, ${ }^{\star}$ C. R. Daubert, ${ }^{\star}$ \\ M. A. Drake, ${ }^{\star}$ and M. Gumpertz† \\ *Department of Food Science and \\ †Department of Statistics \\ North Carolina State University, Raleigh 27695
}

\section{ABSTRACT}

This study investigated the sensory and rheological properties of young cheeses in order to better understand perceived cheese texture. Mozzarella and Monterey Jacks were tested at 4, 10, 17, and $38 \mathrm{~d}$ of age; process cheese was tested at $4 \mathrm{~d}$. Rheological methods were used to determine the linear and nonlinear viscoelastic and fracture properties. A trained sensory panel developed a descriptive language and reference scales to evaluate cheese texture. All methods differentiated the cheeses by variety. Principal component analysis of sensory texture revealed that three principal components explained $96.1 \%$ of the total variation in the cheeses. The perception of firmness decreased as the cheeses aged, whereas the perception of springiness increased. Principal component analysis of the rheological parameters (three principal components: $87.9 \%$ of the variance) showed that the cheeses' solidlike response (storage modulus and fracture modulus) decreased during aging, while phase angle, maximum compliance, and retardation time increased. Analysis of the instrumental and sensory parameters (three principal components: $82.1 \%$ of the variance) revealed groupings of parameters according to cheese rigidity, resiliency, and chewdown texture. Rheological properties were highly associated with rigidity and resiliency, but less so with chewdown texture.

(Key words: cheese, texture, rheology, sensory)

\footnotetext{
Abbreviation key: $\mathbf{J}=$ compliance, $\mathbf{P C}=$ principal component, $\gamma=$ strain, $\gamma_{\mathrm{t} \text {-true }}=$ true shear strain, $\delta=$ phase angle, $\sigma=$ stress, $\sigma_{\mathrm{t}}=$ true shear stress, $\varphi_{\mathrm{s}}=$ angular deformation of capstan curved section. [Some abbreviations are also defined in Table 2.]

Received November 27, 2002.

Accepted May 12, 2003.

Corresponding author: E. A. Foedgeding; e-mail: allen_foegeding@ ncsu.edu.
}

\section{INTRODUCTION}

Cheese is considered an ideal food due to its high nutrition, density, convenience, variety, availability, and good taste (Bogue et al., 1999). One consumer expectation is that the selected cheese possesses an expected texture, characteristic of that particular variety. Texture is an important characteristic used to differentiate many cheese varieties (Antoniou et al., 2000; Wendin et al., 2000) and is considered by the consumer to be a determinant of overall quality and preference ( Lee et al., 1978; Adda et al., 1982; Guinard and Mazzucchelli, 1996).

Many of the major changes in cheese structure, which ultimately affects final texture, occur during storage. Typically, as cheeses age, a decrease in firmness (or softening) of the body occurs. Two phases of texture development during storage have been identified. Phase one occurs within the first 7 to $14 \mathrm{~d}$ after production. During this time, the rubbery texture of the young cheese is converted into the more smooth characteristic texture of the specific variety. In this phase, hydrolysis of about $20 \%$ of the $\alpha_{\mathrm{s} 1}$-CN by residual coagulant occurs, as well as a redistribution of water within the cheese network (de Jong, 1976; Lawrence et al., 1987; Kindstedt et al., 1992; McMahon et al., 1999). A more gradual change in cheese texture occurs during phase two of ripening. During this time, the remaining $\alpha_{\mathrm{s} 1}-\mathrm{CN}$ and the other caseins are hydrolyzed. Unlike phase one, which takes only days, phase two occurs over a period of months (Lawrence et al., 1987).

Cheese is a viscoelastic material in that it exhibits both solid-like and fluid-like behavior (van Vliet and Walstra, 1983; Konstance and Holsinger, 1992; Taneya et al., 1992). Small strain dynamic rheological methods are nondestructive, conducted within the linear viscoelastic region, and determine the elastic and viscous nature of cheese. Large strain rheological methods determine rheological properties that occur outside of the linear viscoelastic region and characterize the nonlinear and fracture properties of the material. 
Rheological methods characterize the physical properties of cheese; however, they must be paired with a human psychophysical interpretation of the tactile and visual perceptions that occur when consuming cheese in order to completely understand what causes differences in cheese texture. Szczesniak (1963) developed a standard classification system for qualifying textural perception. The sensory texture profile method was developed, and this method profiles the entire textural image from first bite through postmastication. Since then, many variations on the standard reference scale have been developed as well as methods by which textural lexicons can be generated (Munoz and Civille, 1998). Methods to improve evaluation techniques have also been explored. Drake et al. (1999a) showed that both hand and mouth evaluation similarly differentiated the texture of a variety of cheeses. Sensory descriptive methods have been used to determine what characteristics of cheeses are most desired by consumers and to differentiate different cheese varieties (McEwan et al., 1989; Bogue et al., 1999; Murray and Delahunty, 2000).

Whereas instrumental measurements of hardness or rigidity have correlated well with sensory hardness, instrumental techniques generally do not accurately profile the entire sensory textural experience (Lee et al., 1978; Chen et al., 1979; Casiraghi et al., 1989). There are many complications associated with developing imitative tests. Mimicking the human sensory experience requires simulating physical changes that occur in the mouth due to saliva interactions, phase changes, and temperature changes. Also, mastication is a dynamic process and traditional rheological tests measure only a 'single' event: the forces and deformations associated with 'first' and sometimes 'second' bite during consumption (Christensen, 1984; Wilkinson et al., 2000). An alternative approach is to accurately measure fundamental rheological properties and determine their role in sensory texture. Fundamental rheological properties are theoretically linked to gel network structure and interactions and can therefore provide insight into the molecular basis of texture.

A comprehensive characterization to define the transitions that occur during the early stages of maturation would aid in deciphering the texture maturation process of cheeses. This investigation is part of a collaborative investigation with the University of Wisconsin and Utah State University on the physical, chemical, microstructural and sensory changes occurring in cheese during the first $38 \mathrm{~d}$ of aging. The objectives of this research were threefold: first, to define the fundamental rheological properties of young cheeses and to see how such properties change as the cheeses age, including linear viscoelastic properties and fracture properties; second, to determine the human perception of the texture of such cheeses over the entire range of mastication; and third, to relate these physical and perceptual definitions to better understand what governs texture in cheeses.

\section{MATERIALS AND METHODS}

\section{Material Description}

Mozzarella, Monterey Jack, and high melt process cheese (referred to as process cheese) were made on two different occasions and collected at the time of manufacture. Mozzarella cheeses were manufactured by Alto Dairy Cooperative (Waupun, WI), Monterey Jacks by Meister Cheese Company (Muscoda, WI), and process cheeses by Kraft (Glenview, IL). Mozzarella was low-moisture, part skim, cultured and made according to the pasta filata process. There was some direct salting at the mixer stage and then it was brine salted. Monterey Jack cheese was directly salted and made by a traditional process. Process cheese was made by a proprietary process that restricted the melting characteristics. Moisture, fat, and protein for Mozzarella, Monterey Jack, and process cheese were 51.2, 39.4 , and $40 \%$; $19.9,34.4$, and $32.1 \%$; and $20.6,22.8$, and $19.1 \%$, respectively. Cheeses were collected at the University of Wisconsin and shipped to North Carolina State University immediately following manufacture using temperature-controlled packaging materials; and all aging occurred at North Carolina State University. Two replications, representing different times of manufacturing, were tested for each cheese. Cheeses were stored at $4^{\circ} \mathrm{C}$ in 4.5 -kg blocks in Cryovac B series, vacuum-sealed bags. Testing of the Mozzarella and Monterey Jacks occurred at 4, 10, 17, and $38 \mathrm{~d}$ of age; process cheese was tested at $4 \mathrm{~d}$ of age. Approximately $3 \mathrm{~cm}$ of the outer rind of the cheeses was discarded immediately before sample preparation; additionally, cheeses were allowed to temper to room temperature before rheological testing.

\section{Rheological Analysis}

Small strain oscillatory analysis. Dynamic oscillatory measurements were performed using a Bohlin VOR controlled-strain rheometer (Bohlin Reologi AB, Lund, Sweden) fitted with $30-\mathrm{mm}$ diameter serrated parallel plates and an $11.085-\mathrm{g} \cdot \mathrm{cm}$ torque bar. The use of the serrated plates prevented specimen slippage. Cheeses were sliced to a 2-mm thickness and placed onto the lower plate surface; the upper plate was then lowered to a 2-mm gap. The edges of the samples were cut to the dimensions of the plates and a thin film of synthetic lubricant (Superlube, Loctite Corporation, 
Rocky Hill, CT) was applied to the exposed edges of the sample to minimize moisture loss. Samples were equilibrated to $25^{\circ} \mathrm{C}$ before testing.

Values of complex modulus $\left(\mathbf{G}^{*}\right)$, storage modulus $\left(\mathbf{G}^{\prime}\right)$, loss modulus $\left(\mathbf{G}^{\prime \prime}\right)$, and phase angle $(\delta)$ were obtained under two conditions. First, strain sweeps were run on all samples to determine the linear viscoelastic region. Frequencies of $0.001,0.01,0.1$, and $1.0 \mathrm{~Hz}$ were observed over a strain range of $1.5 \times 10^{-4}$ to $1.5 \times$ $10^{-1}$. These frequencies correspond to maximum strain rates of $0.047,0.47,4.7$, and $47 \mathrm{~s}^{-1}$, which allowed for comparison to large strain data collected at similar rates (see large strain analysis). Second, frequency sweeps were done on all samples to characterize changes in the viscoelastic behavior with time. Three frequency sweeps were completed on each treatment replication at a constant strain within the linear region from 0.001 to $20 \mathrm{~Hz}$ then returning to $0.001 \mathrm{~Hz}$. Measurements of $\mathrm{G}^{*}, \mathrm{G}^{\prime}, \mathrm{G}^{\prime \prime}$, and $\delta$ at $0.1 \mathrm{~Hz}$ were used for statistical analysis, as this frequency falls within a known range of chewing frequencies (Sharma and Sherman, 1973).

Creep analysis. Creep and creep recovery tests were completed using a Stress Tech controlled-stress rheometer (ATS Rheosystems, Bordentown, NJ) fitted with 20-mm diameter, smooth parallel plates. Temperature was maintained at $25^{\circ} \mathrm{C}$ using an induction heating device. Samples were sliced into 2-mm thick disks and glued to the bottom plate with cyanoacrylate glue (Loctite 100- Loctite Corporation, Rocky Hill, CT). A second dot of the same glue was placed on the top of the sample and the upper plate was lowered to come into contact with the sample. The sample was then trimmed to fit the plate size, and a thin film of synthetic lubricant (Superlube, Loctite Corporation) was applied to prevent moisture loss. All tests were conducted at a stress of $71.9 \mathrm{~Pa}$ (within the linear viscoelastic region as determined by stress sweeps at 1.0 $\mathrm{Hz}$ from 0 to $500 \mathrm{~Pa}$ ). The creep portion of each test consisted of a stress application for $600 \mathrm{~s}$; the stress was removed and strain recovery was measured for an additional $1200 \mathrm{~s}$. Strain rates in this test ranged from $1.7 \times 10^{-5}$ to $1.0 \times 10^{-3} \mathrm{~s}^{-1}$. Three creep-recovery tests were done for each treatment replication.

Retardation time $\left(\lambda_{\text {ret }}\right)$ gives an indication of a characteristic time needed for a substance to deform and is determined by the time required for the delayed strain to reach $63.2 \%$ of its final value (Steffe, 1996). Compliance, defined as the ratio of strain to stress, was monitored as a function of time. Instantaneous compliance $\left(\mathbf{J}_{\mathbf{0}}\right)$ was the compliance at time zero and was determined through extrapolation of the creep curve to time zero. Maximum compliance $\left(\mathbf{J}_{\mathbf{m x}}\right)$ was the peak compliance reached by the material before the constant stress was removed. Percent creep recovery (crp) gives an indication of the degree of elasticity in the material and was calculated using the following relationship:

$$
c r p=\frac{\left(J_{m x}\right)-\left(J_{r}\right)}{\left(J_{m x}\right)} * 100,
$$

where $J_{m x}$ is the maximum creep compliance and $\mathbf{J}_{\mathbf{r}}$ is the compliance after recovery.

Large strain analysis. Torsional methods were used to determine the nonlinear and fracture properties of the cheeses. Cylinders of cheese were formed using a $19-\mathrm{mm}$ i.d. cork borer. The cylinders were cut to a length of $28.7 \mathrm{~mm}$, and plastic disks (Gel Consultants, Raleigh, NC) were glued to the ends of the cylinder using cyanoacrylate glue (Loctite 100-Loctite Corporation) to enable the samples to be mounted to the grinding and twisting apparatuses. The cylinders were shaped into a capstan shape having a minimum diameter of 10-mm using a precision grinding machine (Gel Consultants, Raleigh, NC). Samples were twisted using a Haake 550 viscotester (Gebruder Haake GmbH, Karlsruhe, Germany) fitted with a fabricated apparatus that enabled torsional measurement (Truong and Daubert, 2001). The capstans were twisted at 0.045 , 0.45 , and $4.5 \mathrm{rpm}$, and three samples at each speed for each treatment replication were tested. These speeds correspond to strain rates of $0.0047,0.047$, and $0.47 \mathrm{~s}^{-}$ ${ }^{1}$ allowing for comparison with strain sweeps at similar strain rates.

True shear stress $\left(\sigma_{t}\right)$ and true shear strain $\left(\gamma_{\text {t-true }}\right)$ were calculated at each point from time at zero to time at fracture using the following relationships (Nadai, 1937; Diehl et al., 1979; Hamann, 1983):

$$
\begin{gathered}
\sigma_{t}=\frac{2 K M}{\pi r_{\min }^{3}} \\
\gamma_{t}=\frac{2 K \phi_{s}}{\pi_{\min }^{3} Q} \\
\gamma_{t \text {-true }}=\ln \left[1+\frac{\gamma_{t}^{2}}{2}+\gamma_{t}\left(1+\frac{\gamma_{t}^{2}}{4}\right)^{1 / 2}\right],
\end{gathered}
$$

where $r_{\min }$ is the minimum capstan radius, $\mathrm{K}$ is the shape factor constant (equal to 1.08), $\mathrm{M}$ is the torque $(\mathrm{N} \mathrm{m}), \varphi_{\mathrm{s}}$ is the angular deformation of the curved section, and $\mathrm{Q}$ is the curvature section constant (equal to $8.45 \times 10^{-6} \mathrm{~m}^{-3}$ ).

From these equations, the shear fracture modulus $\left(\mathbf{G}_{\mathbf{f}}\right)$ was calculated according to the following equation (Bowland and Foegeding, 1995): 


$$
\mathrm{G}_{f}=\frac{\sigma_{t}}{\gamma_{t-\text { true }}}
$$

where $\sigma_{\mathrm{t}}$ is the true shear stress and $\gamma_{\mathrm{t} \text {-true }}$ is the true shear strain.

\section{Sensory Analysis}

Descriptive sensory analysis techniques were used to describe the human textural perception of the cheeses. A panel of 15 people received approximately $10 \mathrm{~h}$ of training encompassing evaluation techniques, texture term definitions, and use of reference scales. Cheeses were evaluated using hand, mouth, and residual techniques. The terms used to define texture are outlined in Table 1 (Drake et al., 1999a; Gwartney et al., 2002) sequentially as they were evaluated by panelists. The panel used a 15-point product-specific reference scale for each term, anchored on the right (high numbers) with "very" and on the left (low numbers) with "not" (Table 1). During training, the panel was presented cheeses having textural extremes for each term representing the anchors of each scale. The panel was then presented with more common, wellknown cheeses, and through panel consensus, scores were assigned to these cheeses, thereby completing the reference scales. Through training and group discussion, panel variability was minimized.

At each sample evaluation session, three to six cheese samples were evaluated. Each cheese sample was cut into $1.27-\mathrm{cm}^{3}$ cubes, and each panelist was given four cubes of cheese per sample. The samples were presented at room temperature in 2-oz plastic sample cups sealed with plastic lids (Sweetheart Cup Company Inc., Owings Mills, MD) to minimize moisture loss, and samples were identified by a random three-digit numerical code. The testing occurred in individual booths under normal lighting conditions. At each session, panelists were given appropriate references, prepared in the same manner as the sample, and a warm-up sample was evaluated before sample evaluation. The warm-up sample was the same at each evaluation session and was used extensively during training. Panelists were also given water and napkins for mouth and hand cleansing and were instructed to expectorate all samples in order to measure residual mouthfeel. Testing occurred at the same time each day, and the samples were randomized so that each age of each cheese was evaluated three times by each panelist over a 2 -d period.

\section{Statistical Analysis}

The large strain, nonlinear data were fitted to a power law curve using Sigma Plot (version 6.10, SPSS,
Inc., Chicago, IL). Correlation analysis (PROC CORR) using the SAS statistical software package (version 8.2, SAS Institute, Inc., Cary, NC) of the rheological data allowed for determination of relationships between individual instrumental parameters. The experimental unit used for the correlation analysis of the rheological results was the mean of each variety $x$ age $\times$ batch treatment $(n=18)$. Principal component analysis (PROC PRINCOMP) of the rheological results was used to decrease the number of dimensions (see Table 2 for original dimensions) and to make visual comparisons of how the instrumental variables differentiated the cheeses. The experimental unit used for the correlation analysis was also used for the principal component analysis.

Statistical analysis was done using the SAS statistical software package (version 8.2, SAS Institute, Inc.). A general linear model (PROC GLM) was used to analyze $\mathrm{G}^{\prime}, \mathrm{G}^{\prime \prime}, \delta, \mathrm{G}_{\mathrm{f}}$, and $\mathrm{J}_{\mathrm{mx}}$. Analysis of variance (PROC MIXED) was done on the sensory terms and least squares means were calculated; pair-wise comparison of significant differences between means of cheeses was done and significance was established at $P \leq 0.05$ (age effects within cheese variety were compared for the sensory data). A repeated measures model was utilized and each sensory term (see Table 1) was determined and analyzed in a $2 \times 4+1 \times 1$ (variety $\times$ age + variety $\times$ age) incomplete cross factorial design:

$$
\begin{gathered}
Y_{i j k l m}=\mu+\alpha_{i}+\beta_{j}+(\alpha \beta)_{i j}+S_{k}+B_{l}+E_{k l m} . \\
\text { Sensory term }=\text { overall mean }+(\text { variety })_{\mathrm{i}}+(\text { age })_{\mathrm{j}}+ \\
(\text { variety } \times \text { age })_{\mathrm{ij}}+(\text { judge })_{\mathrm{k}}+(\text { batch })_{1}+(\text { error })_{\mathrm{klm}},
\end{gathered}
$$

where

$$
\begin{aligned}
\mathrm{i} & =1,2,3,4 \text { (age); } \\
\mathrm{j} & =1,2,3 \text { (variety); } \\
\mathrm{k} & =1,2,3,4,5,6,7,8,9,10,11,12,13,14,15 \text { (judge); } \\
\mathrm{l} & =1,2 \text { (batch); and } \\
\mathrm{m} & =1,2,3 \text { (replicate) }
\end{aligned}
$$

Correlation analyses (PROC CORR) of the sensory terms and the sensory and rheological parameters combined were used to determine individual relationships among sensory data and among sensory and instrumental data. The experimental unit used for analysis of the sensory terms was the least squares means of each variety $\times$ age $\times$ batch treatment $(n=18)$; the experimental unit used for analysis of the instrumental terms was the means of each variety $\times$ age $\times$ batch treatment $(\mathrm{n}=18)$. Principal component analysis (PROC PRINCOMP) was used to make visual comparisons of how the sensory data alone differentiated the 
Table 1. Language used to evaluate cheese texture perception; evaluation techniques, term definitions, and references are given.

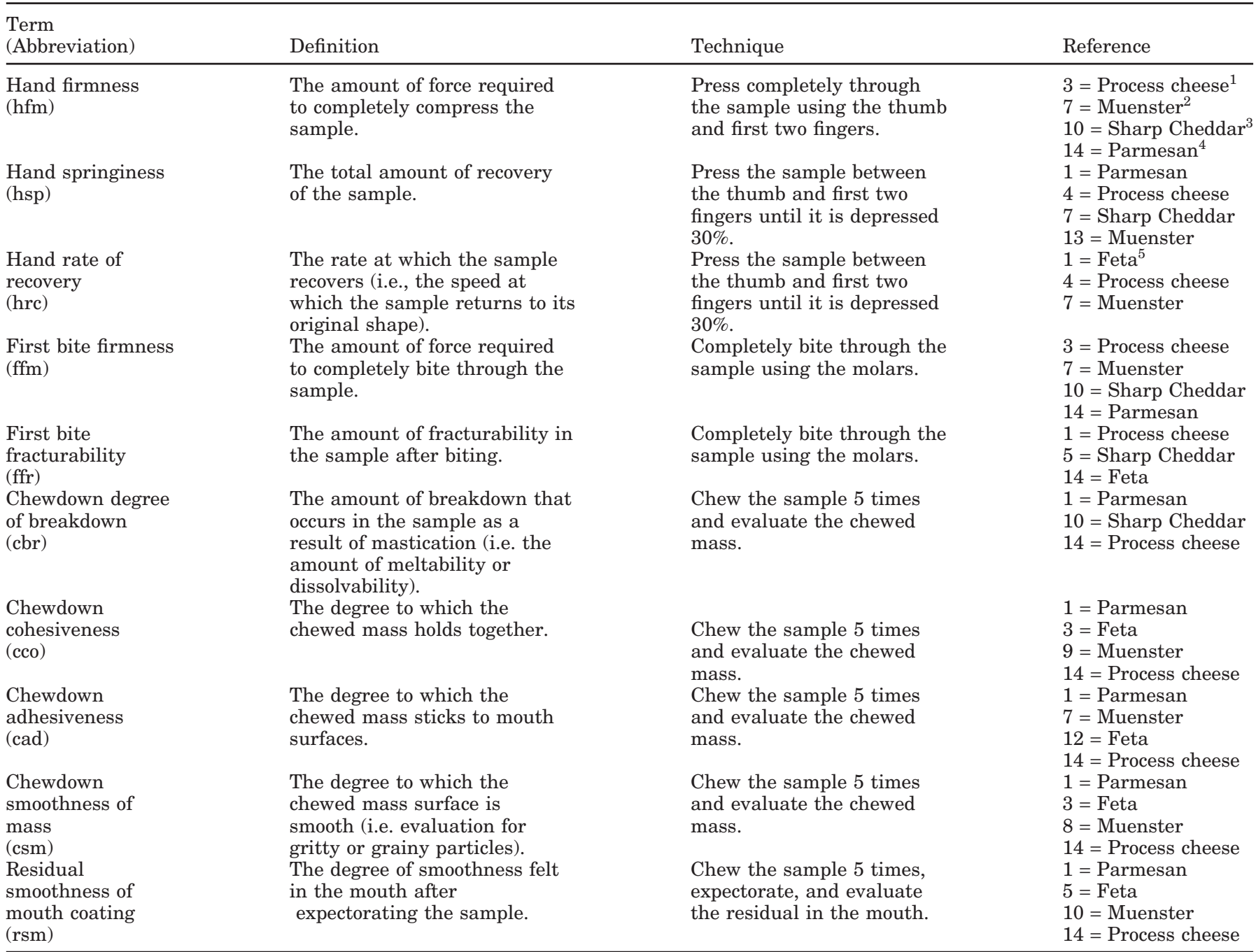

${ }^{1}$ Process cheese: Velveeta brand 907-g loaf (Kraft Foods North America; Glenview, IL).

${ }^{2}$ Muenster: Harris Teeter brand (Harris Teeter; Matthews, NC).

${ }^{3}$ Sharp Cheddar: Kraft brand 227-g block (Kraft Foods; Glenview, IL).

${ }^{4}$ Parmesan: Kraft brand 113-g triangle (Kraft Foods; Glenview, IL).

${ }^{5}$ Feta: Athenos brand 227-g block (Churny Company, Inc.; Weyauwega, WI).

Table 2. Definitions of parameters used for statistical analysis.

\begin{tabular}{ll}
\hline Symbol & Definition \\
\hline $\mathrm{G}^{*}$ & Complex modulus-taken from small strain frequency sweep tests at $0.1 \mathrm{~Hz}$ \\
$\mathrm{G}^{\prime}$ & Storage modulus-taken from small strain frequency sweep tests at $0.1 \mathrm{~Hz}$ \\
$\mathrm{G}^{\prime \prime}$ & Loss modulus-taken from small strain frequency sweep tests at $0.1 \mathrm{~Hz}$ \\
$\delta$ & Phase angle-taken from small strain frequency sweep tests at $0.1 \mathrm{~Hz}$ \\
$\mathrm{G}_{\mathrm{f}}$ & Fracture modulus-taken from large strain torsional tests at $4.5 \mathrm{rpm}$ \\
$\mathrm{J}_{\mathrm{o}}$ & Instantaneous compliance-compliance at time 0 s from creep recovery tests \\
$\mathrm{J}_{\mathrm{mx}}$ & Maximum compliance-from creep recovery tests; maximum compliance value just before stress is released \\
$\mathrm{crp}$ & Percent creep recovery-from creep recovery tests; relative amount of recovery after the \\
& material is subjected to a constant stress over a given time period \\
$\lambda_{\text {ret }}$ & Retardation time-time for material to reach $1-1 / \mathrm{e}(63.2 \%)$ of the delayed strain (from creep \\
\hline
\end{tabular}


cheeses as well as how combining the instrumental and sensory variables together could differentiate the cheeses.

\section{RESULTS AND DISCUSSION}

\section{Viscoelastic Properties}

Controlled-strain testing. Results of the viscoelastic characterization of each of the cheeses are shown in Figure 1. Overall, the magnitude of the storage modulus $\left(G^{\prime}\right)$ was higher for all samples than the magnitude of the loss modulus $\left(G^{\prime \prime}\right)$, and $G^{\prime}$ increased with increasing frequency. These trends are general characteristics of viscoelastic, weak gels (Kavanagh and Ross-Murphy, 1998) and have been observed with cheese (Ma et al., 1996; Nolan et al., 1989; Tunick, 2000). The magnitude of $\mathrm{G}^{\prime}$ in Mozzarella and Monterey Jacks changed slightly with age; however, a comparison of values determined at $0.1 \mathrm{~Hz}$ showed no significant differences with age.

The changes in phase angle $(\delta)$ in the cheeses can be seen in Figure 2. In a purely viscous material the $\delta$ is $90^{\circ}$ and $0^{\circ}$ for a pure elastic material. The pattern of response as frequency changes is very similar in all of the cheeses tested; such a pattern shows the timedependent nature of the stress/strain application in the cheeses, and this pattern can be used to differentiate cheeses from other viscoelastic, weak gels. At very low frequencies $(0.001 \mathrm{~Hz}), \delta$ is relatively high, showing the dominant effect of the viscous component; the cheeses behave more fluid-like when deformed at slower speeds. As the frequency of strain application increases $(0.01$ to $1.0 \mathrm{~Hz}), \delta$ levels, showing that the speed has less of an influence on the relative effects of the viscoelastic properties. Finally, at very high frequencies, $\delta$ is low, showing the dominant effect of the elastic component; the cheeses behave more "solidlike" at such higher speeds.

Controlled-stress testing. The results from the creep recovery analysis are shown in Figure 3. The varietal differences are apparent; Mozzarella cheese showed the highest overall compliance, Monterey Jack had less overall compliance, and process cheese showed the lowest compliance. In general, as the cheeses aged, $\mathrm{J}_{\mathrm{mx}}$ increased although there was no significant difference due to aging. Process cheese showed the highest creep recovery, with compliance almost returning to zero in the recovery phase.

\section{Nonlinear and Fracture Properties}

The fracture modulus $\left(\mathrm{G}_{\mathrm{f}}\right)$ at varying strain rates for all of the cheeses are given in Figure 4. In all treatments, an increase in $\mathrm{G}_{\mathrm{f}}$ was observed as strain rate increased, confirming the viscoelastic, time-dependent nature of the cheeses. There were no consistent trends seen with aging.

The linear, nonlinear, and fracture properties of Mozzarella and Monterey Jacks were compared at two strain rates $\left(0.047\right.$ and $\left.0.47 \mathrm{~s}^{-1}\right)$ and are shown in Figure 5. Overall, the range of strain characterized using these methods was 0.001 to $~ 2.0$, and stress was characterized from 18 to $40,000 \mathrm{~Pa}$, representing three orders of magnitude in both parameters. A gap in the curve was observed between $\sim 0.01$ and 0.1 strain. This region could not be measured due to the strain limitations of the equipment used.

The maximum linear viscoelastic strain seen in these cheeses was 0.017 (Figure 5a); these results confirm the weak physical gel classification of these materials. The maximum linear strain for strong physical gels is $\gamma_{\text {lin }}>\sim 0.2$, whereas weak physical gels show a maximum linear strain up to 1000 times less (Kavanagh and Ross-Murphy, 1998). The shape of the stressstrain curve in the nonlinear region was fit to a power law model (data not shown) and parameters derived from the model were analyzed for correlation with sensory parameters. Because no correlations were found, further analysis of the data was not pursued.

\section{Differentiation by Sensory Means}

Five sensory terms were able to differentiate the ages of the cheeses within varieties as shown in Table 3. Moreover, unlike specific comparisons in rheological properties, cheese texture changed significantly $(P<$ 0.05) with age. Mozzarella and Monterey Jack both became significantly less firm over time (as measured by the mouth). These cheeses appeared to break down more in the mouth after being chewed as the cheese aged. The degree to which Monterey Jack broke down over time was higher than the Mozzarella. Both Mozzarella and Monterey Jack became more cohesive after chewdown over time. Mozzarella did not change in mouth adhesiveness over time, whereas Monterey Jack did become significantly more adhesive. Mozzarella and Monterey Jack also became significantly smoother after chewdown over time.

\section{Correlation Analysis}

Relationships among rheological parameters. Table 2 defines the rheological parameters used in statistical analysis. The parameters of $G^{\prime}, G^{\prime \prime}$, and $G_{f}$ generally increased with network firmness, while $J_{\mathrm{mx}}$ decreased. Correlations bear out this relationship (Table 4). However, the variation in correlation coefficients indicates that these parameters were each mea- 

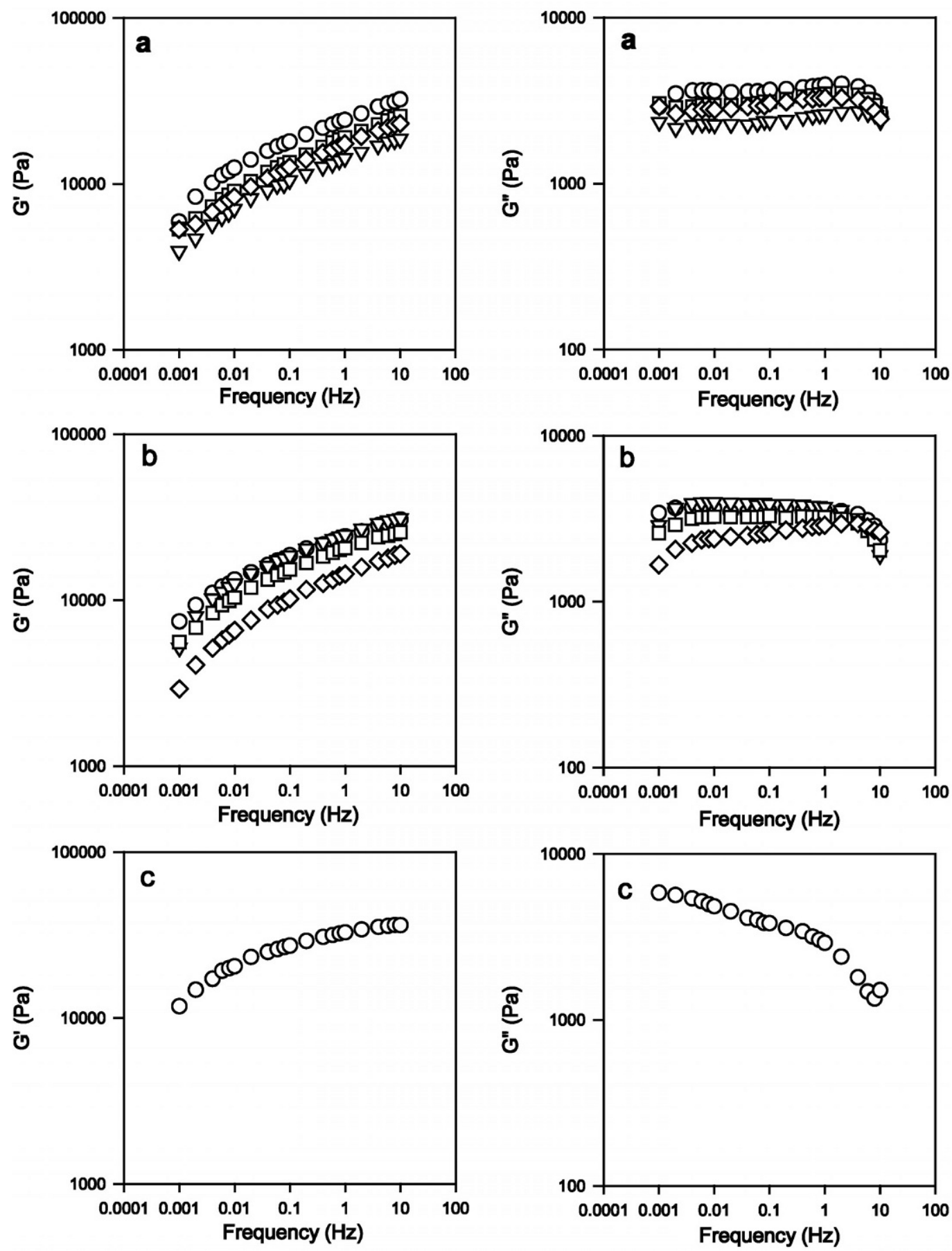

Figure 1. Storage modulus $\left(\mathrm{G}^{\prime}\right)$ and loss modulus $\left(\mathrm{G}^{\prime \prime}\right)$ over changing frequencies for Mozzarella (a), Monterey Jack (b), and process (c) cheeses at $4 \mathrm{~d}(\bigcirc), 10 \mathrm{~d}(\nabla), 17 \mathrm{~d}(\square)$, and $38 \mathrm{~d}(\diamond)$ of age. Values are the average for two replications.

suring different properties; $\mathrm{G}_{\mathrm{f}}$ is measured at fracture, whereas the others were measured within or around the linear viscoelastic region. The parameters of $\delta, \lambda_{\text {ret }}$, and crp are indicators of viscoelastic nature of cheese, along with the ability to recover from a deformation. In general, as the cheese networks broke down and the firmness and elastic elements decreased, the viscoelastic response became more viscous, and the recovery became less. This too is reflected in the magnitude and direction of the correlations.

Analysis of rheological data showed that three principal components were able to explain $87.9 \%$ of the 

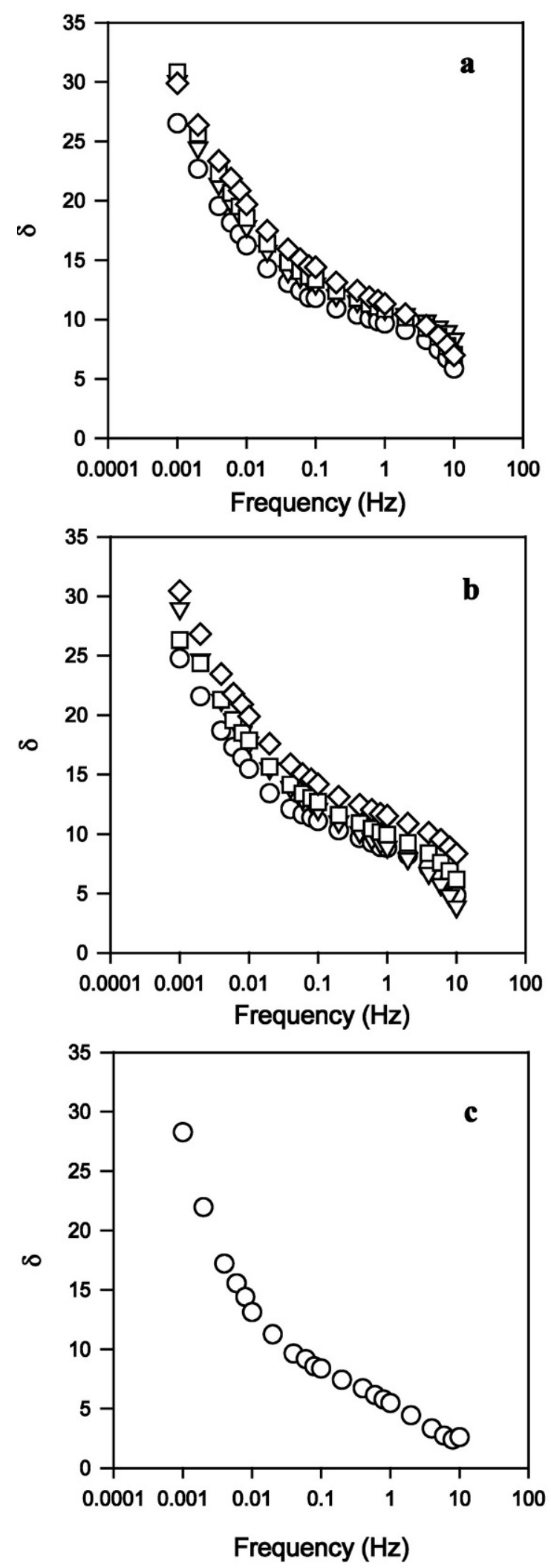

Figure 2. Phase angle $(\delta)$ over changing frequencies for Mozzarella (a), Monterey Jack (b), and process (c) cheeses at $4 \mathrm{~d}(\bigcirc), 10 \mathrm{~d}(\nabla), 17$ $\mathrm{d}(\square)$, and $38 \mathrm{~d}(\diamond)$ of age. Values are the average for two replications.
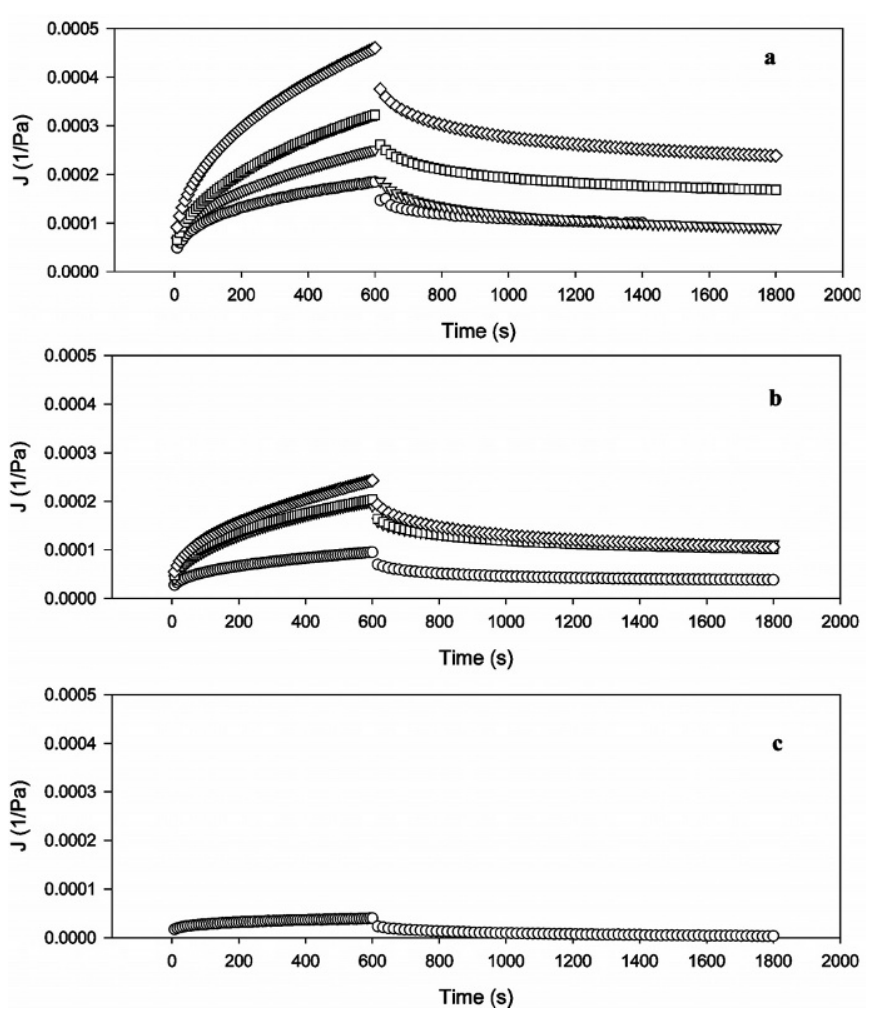

Figure 3. Creep recovery curves for Mozzarella (a), Monterey Jack (b), and process (c) cheeses at $4 \mathrm{~d}(\bigcirc), 10 \mathrm{~d}(\nabla), 17 \mathrm{~d}(\square)$, and $38 \mathrm{~d}$ $(\diamond)$ of age. Values are the average for two replications.

variation seen in the cheese. Figure 6 shows principal components (PC) one (PC1; $61.9 \%$ of the total variation) and two (PC2; $14.0 \%$ of the total variation). Principal component one distinguished the cheeses by age; as the cheeses aged, their loadings on PC1 decreased. Analysis of the eigenvector loadings revealed that high PC1 values related to high $G^{\prime}$ and $G_{f}$, both measurements of the solid-like component of the materials. It also related to lower $\delta, \mathrm{J}_{\mathrm{mx}}$, and $\lambda_{\text {ret. }}$ Principal component two related most to the viscous component of the cheeses $\left(G^{\prime \prime}\right)$ and differentiated the natural cheeses from process cheese with the exceptions of Mozzarella $10 \mathrm{~d}$ and Monterey Jack $38 \mathrm{~d}$, which loaded similarly to process cheese. The instrumental data also differentiated the natural cheeses by type (data not shown). Generally, Monterey Jack loaded higher on PC3 than Mozzarella cheese.

Relationships among sensory terms. Hand and first-bite firmness were highly correlated (Table 5). Both firmness measurements were correlated with fracturability, showing that the firmer cheeses tended to fracture into more pieces when force was added. Springiness and rate of recovery were also highly correlated; cheeses that showed large amounts of total 

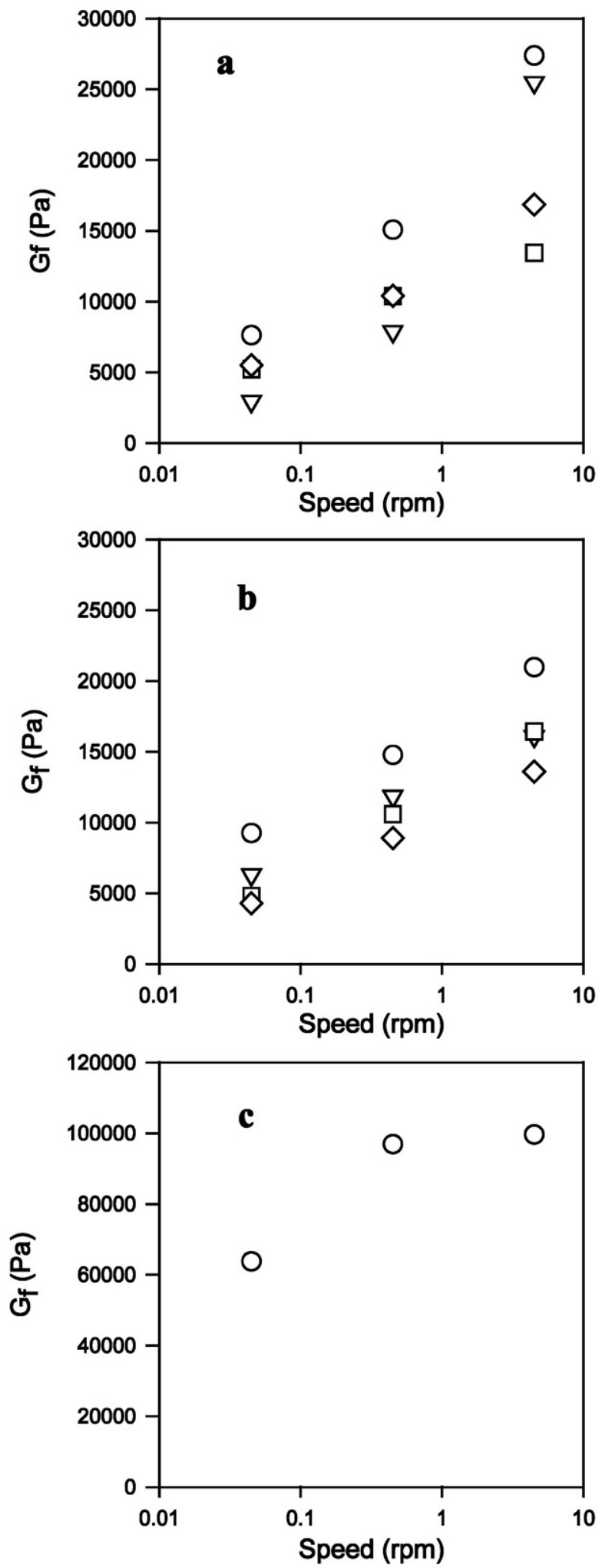

Figure 4. Fracture modulus $\left(\mathrm{G}_{\mathrm{f}}\right)$ of Mozzarella (a), Monterey Jack (b), and process (c) cheeses at $4 \mathrm{~d}(\bigcirc), 10 \mathrm{~d}(\nabla), 17 \mathrm{~d}(\square)$, and $38 \mathrm{~d}$ $(\diamond)$ of age. Values are the average for two replications. recovery after depression recovered at a faster rate than cheeses showing a lesser total degree of recovery. Negative correlation was seen between fracturability and certain chewdown terms (breakdown, cohesiveness, and smoothness), implying that when cheeses fractured into many pieces upon biting, those pieces maintained their individuality as one chewed. All of the chewdown and residual terms were highly correlated with each other. Highly cohesive cheeses were perceived as smooth and adhered to the mouth surfaces; upon expectoration, the mouth coating was expected to be high due to the high adhesion of the chewed mass, and the smoothness of the coating would also be expected to be high, since the original mass was perceived as smooth. Similar relationships have been reported. Drake et al. (1999a) found that hand and mouth evaluated firmness were highly correlated; mouth cohesiveness, smoothness, and stickiness to the teeth were also correlated. Like the results reported in this paper, they also found that crumbly cheeses (i.e., high fracturability) were low in mouth smoothness, cohesiveness, and adhesiveness.

For the sensory results, $96.1 \%$ of the total variation in samples could be explained by three principal components. Figure 7 shows PC1 and PC2. Principal component one explained $55.8 \%$ of the variance seen in the samples and was able to chronologically differentiate the natural cheeses (Mozzarella and Monterey Jack) according to age; as the cheeses aged, they showed higher PC1 values. Principal component two accounted for $26.1 \%$ of the total sample variation and also established the age-dependent trends. Hand and mouth firmness and fracturability loaded positively on PC2, whereas hand springiness and rate of recovery loaded negatively. As the cheese aged, they became less firm and fractured less while, simultaneously, they became springier and recovered more quickly when depressed.

Process cheese showed the highest values of PC1 and PC2 of any of the cheeses. It was very firm, not springy, and had a very cohesive, smooth bolus that highly adhered to mouth surfaces. These characteristics distinguished it from the natural cheeses.

Relationships among instrumental and sensory terms. The correlations observed between the instrumental and sensory data are shown in Table 6 . Seven of the 10 rheological properties correlated with hand firmness, while five correlated with first-bite firmness. Positive correlations were observed between perceived firmness and $G^{*}, G^{\prime}$, and $G_{f}$. These measurements are ratios of force to deformation and thus would increase with firmness.

Both sensory measures of perceived firmness were highly negatively correlated with $\delta$ and $\mathrm{J}_{\mathrm{mx}}$, as would 

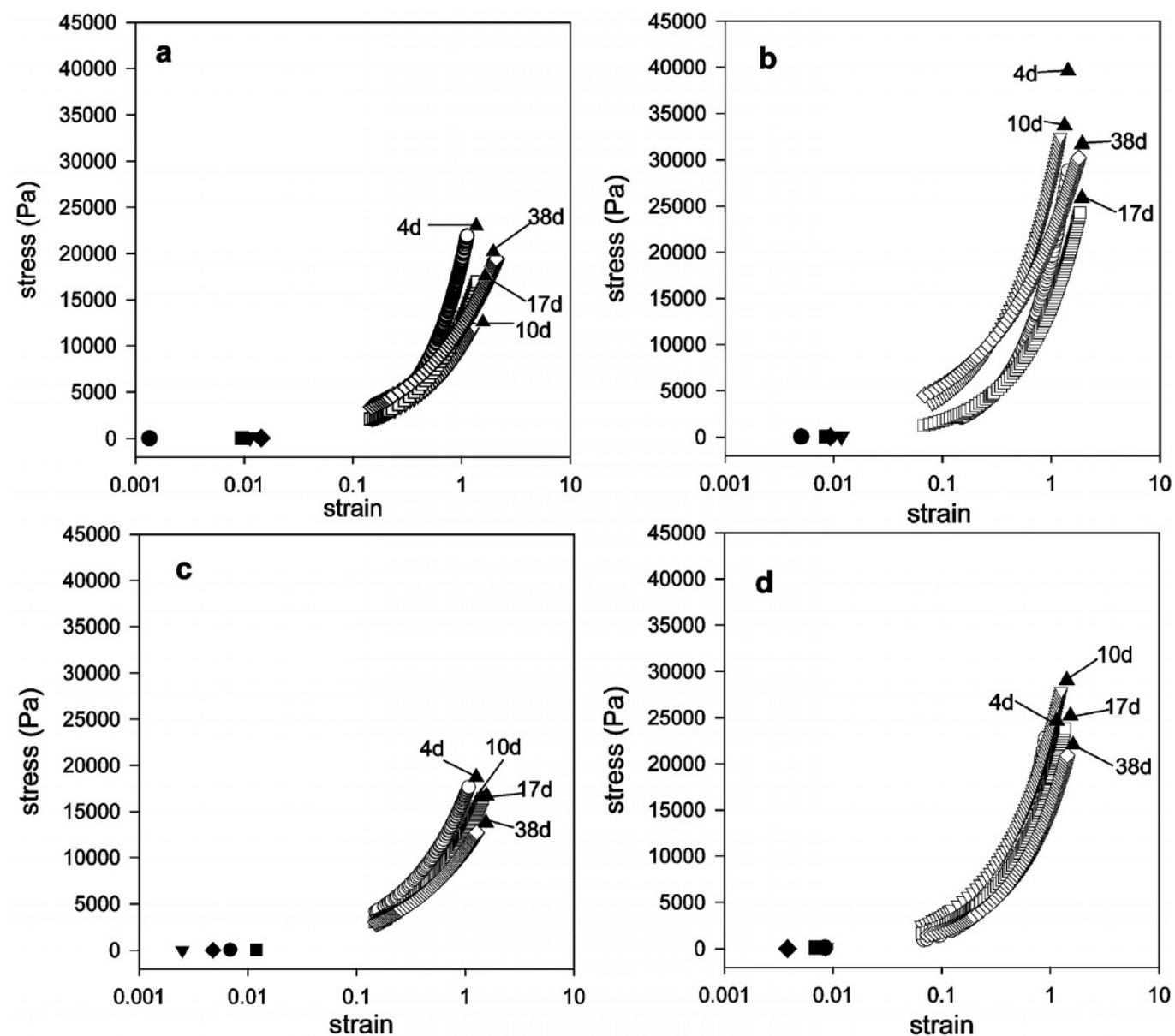

Figure 5. Range of rheological properties for Mozzarella cheese at strain rates of 0.047 (a) and 0.47 (b) $\mathrm{s}^{-1}$ and Monterey Jack at strain rates of 0.047 (c) and 0.47 (d) $\mathrm{s}^{-1}$. Closed shapes represent the strain limit (i.e., endpoint of linear viscoelastic region) from small strain tests at $4 \mathrm{~d}(\bullet), 10 \mathrm{~d}(\boldsymbol{\nabla}), 17 \mathrm{~d}(\mathbf{\square})$, and $38 \mathrm{~d}(\bullet)$ of age. Open shapes represent nonlinear characteristics from torsional tests at $4 \mathrm{~d}(\bigcirc), 10$ $\mathrm{d}(\nabla), 17 \mathrm{~d}(\square)$, and $38 \mathrm{~d}(\diamond)$ of age. Fracture characteristics are also given $(\boldsymbol{\Lambda})$ (ages are given beside symbol). Values are the average for two replications.

be expected based on relationships among rheological parameters (Table 4). This is consistent with other investigations. Drake et al. (1999b) showed that cheeses perceived to be less firm, showed higher com- pliance. The correlation of sensory and rheological methods associated with firmness is not surprising because the evaluations are very similar between instrumental and human techniques. Sensorial firm

Table 3. Sensory differences of ages within cheese varieties (standard errors are given in parentheses). Key for acronyms: First-bite firmness (ffm), chewdown degree of breakdown (cbr), chewdown cohesiveness (cco), chewdown adhesiveness (cad), and chewdown smoothness (csm).

\begin{tabular}{lccllll}
\hline Cheese & Age $(\mathrm{d})$ & $\mathrm{ffm}$ & $\mathrm{cbr}$ & $\mathrm{cco}$ & $\mathrm{cad}$ & $\mathrm{csm}$ \\
\hline Mozzarella & 4 & $8.99^{\mathrm{a}}(0.81)$ & $3.68^{\mathrm{a}}(0.86)$ & $3.34^{\mathrm{a}}(1.06)$ & $3.67^{\mathrm{a}}(0.65)$ & $3.36^{\mathrm{a}}(1.27)$ \\
& 10 & $9.32^{\mathrm{a}}(0.81)$ & $4.61^{\mathrm{ab}}(0.86)$ & $4.07^{\mathrm{ab}}(1.06)$ & $3.95^{\mathrm{a}}(0.65)$ & $4.03^{\mathrm{ab}}(1.27)$ \\
& 17 & $8.33^{\mathrm{ab}}(0.81)$ & $5.47^{\mathrm{b}}(0.86)$ & $5.27^{\mathrm{b}}(1.06)$ & $4.48^{\mathrm{a}}(0.65)$ & $5.05^{\mathrm{b}}(1.27)$ \\
Monterey Jack & 38 & $7.74^{\mathrm{b}}(0.81)$ & $5.41^{\mathrm{b}}(0.86)$ & $5.17^{\mathrm{b}}(1.06)$ & $4.66^{\mathrm{a}}(0.65)$ & $4.91^{\mathrm{b}}(1.27)$ \\
& 4 & $10.03^{\mathrm{a}}(0.81)$ & $4.61^{\mathrm{a}}(0.86)$ & $4.57^{\mathrm{a}}(1.06)$ & $4.16^{\mathrm{a}}(0.65)$ & $4.51^{\mathrm{a}}(1.27)$ \\
& 10 & $9.55^{\mathrm{a}}(0.81)$ & $5.94^{\mathrm{ab}}(0.86)$ & $5.75^{\mathrm{ab}}(1.06)$ & $5.05^{\mathrm{a}}(0.66)$ & $5.43^{\mathrm{ab}}(1.28)$ \\
& 17 & $9.11^{\mathrm{ab}}(0.81)$ & $7.19^{\mathrm{bc}}(0.86)$ & $7.29^{\mathrm{bc}}(1.06)$ & $6.28^{\mathrm{b}}(0.65)$ & $6.47^{\mathrm{bc}}(1.27)$ \\
Process cheese & 38 & $8.27^{\mathrm{b}}(0.81)$ & $8.47^{\mathrm{c}}(0.86)$ & $8.46^{\mathrm{c}}(1.06)$ & $6.86^{\mathrm{b}}(0.65)$ & $7.52^{\mathrm{c}}(1.27)$ \\
\hline
\end{tabular}

${ }^{\mathrm{abc}}$ Means with same superscript are not significantly different at $P>0.05$. 
Table 4. Correlation analysis of instrumental parameters for assessment of cheese texture. Key for instrumental parameters: Complex modulus $\left(G^{*}\right)$, storage modulus $\left(\mathrm{G}^{\prime}\right)$, loss modulus $\left(\mathrm{G}^{\prime \prime}\right)$, phase angle $(\delta)$, fracture modulus $\left(G_{f}\right)$, initial compliance $\left(J_{0}\right)$, maximum compliance $\left(J_{m x}\right)$, retardation time $\left(\lambda_{\text {ret }}\right)$, percent creep recovery (crp).

\begin{tabular}{|c|c|c|c|c|c|c|c|c|c|}
\hline & $\mathrm{G}^{*}$ & $\mathrm{G}^{\prime}$ & $\mathrm{G}^{\prime \prime}$ & $\delta$ & $\mathrm{G}_{\mathrm{f}}$ & $\mathrm{J}_{\mathrm{o}}$ & $\mathrm{J}_{\mathrm{mx}}$ & $\lambda_{\text {ret }}$ & crp \\
\hline$G^{*}$ & 1.000 & $0.999 * * *$ & $0.858 * * *$ & $-0.845 * * *$ & 0.599* & -0.144 & $-0.621^{*}$ & $-0.678^{* *}$ & $0.543 *$ \\
\hline $\mathrm{G}^{\prime}$ & & 1.000 & $0.853 * * *$ & $-0.847 * * *$ & $0.596 *$ & -0.134 & $-0.623^{*}$ & $-0.672^{* *}$ & $0.552 *$ \\
\hline$G^{\prime \prime}$ & & & 1.000 & $-0.507^{*}$ & 0.303 & -0.135 & -0.365 & -0.379 & 0.214 \\
\hline$\delta$ & & & & 1.000 & $-0.675^{* *}$ & 0.065 & $0.831^{* * * *}$ & $0.787 * * *$ & $-0.707 * *$ \\
\hline $\mathrm{G}_{\mathrm{f}}$ & & & & & 1.000 & -0.275 & $-0.573 *$ & $-0.581^{*}$ & $0.806 * * *$ \\
\hline$J_{0}$ & & & & & & 1.000 & -0.087 & 0.197 & -0.039 \\
\hline $\mathrm{J}_{\mathrm{mx}}$ & & & & & & & 1.000 & $0.689 * *$ & $-0.731 * *$ \\
\hline$\lambda_{\text {ret }}$ & & & & & & & & 1.000 & $-0.499 *$ \\
\hline crp & & & & & & & & & 1.000 \\
\hline
\end{tabular}

* Significant at $P \leq 0.05$.

**Significant at $P \leq 0.005$.

*** Significant at $P \leq 0.0001$.

cheeses also showed a positive correlation with percent creep (crp), a measurement of how much a sample returns to its original shape after reaching full strain in a given time period. When compared under constant stress, very firm cheeses have a small full deformation; therefore, the amount of strain change needed for total recovery would be less. In the given time period, firmer cheeses would appear to recover more since the amount of strain change it would have to make for full recovery would be relatively less than the amount of strain change a less firm cheese would have to make in the same time period. Drake et al. (1999b) made similar observations.

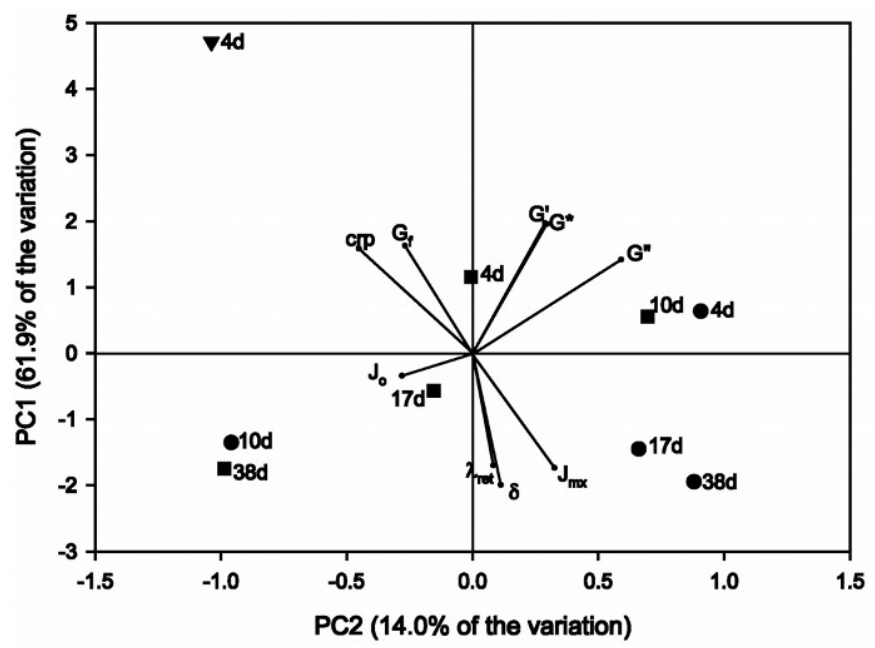

Figure 6. Principal component analysis biplot of instrumental

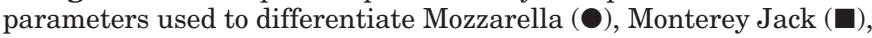
and process $(\boldsymbol{\nabla})$ cheeses by age (indicated by numbers beside symbol). Key for instrumental parameters: Complex modulus $\left(G^{*}\right)$, storage modulus $\left(\mathrm{G}^{\prime}\right)$, loss modulus $\left(\mathrm{G}^{\prime \prime}\right)$, phase angle $(\delta)$, fracture modulus $\left(G_{f}\right)$, initial compliance $\left(J_{0}\right)$, maximum compliance $\left(J_{m x}\right)$, percent creep recovery (crp), and retardation time $\left(\lambda_{\text {ret }}\right)$.
Rheological properties determined within the linear viscoelastic region, $\mathrm{G}^{*}, \mathrm{G}^{\prime}$, and $\delta$, were only correlated with firmness (Table 6). The four properties determined from creep testing were correlated with firmness, and also with first bite fracturability, chewdown adhesiveness and residual smoothness. The fracture modulus was correlated with five sensory properties, including two chewdown terms (Table 6). The combination of fracture and creep testing provides five rheological properties that are correlated with eight of the 10 sensory terms. Although it is clear that some of the correlation coefficients are low, the fact that they are all significant shows promise that the rheological property is associated with sensory detectable texture. Given the limited number and types of cheeses included in this study, no significant chewdown parameters of cohesiveness and smoothness were not correlated with any rheological parameters. This implies that these textural sensations are not being measured, either directly or indirectly, by any of the rheological properties evaluated.

Principal component analysis on the instrumental and sensory variables together defined $83.6 \%$ of the variation in these cheeses. Figure 8 shows PC1 and PC2 from this analysis. When looking at just the loadings of the dependent variables on the biplot of PC1 versus PC2, three groupings of terms are observed. The first grouping is seen in the upper left quadrant and includes $G^{*}, G^{\prime}, G_{f}$, and sensory firmness. All of these terms relate to the rigidity of the material. The second grouping of terms is seen in the center of the lower two quadrants and includes $\mathrm{J}_{\mathrm{mx}}, \lambda_{\text {ret }}, \delta$, sensory springiness, and sensory rate of recovery. All of these terms relate to the resiliency of the samples. Finally, the third grouping is in the upper right quadrant and consists of only the sensory chewdown and residual 
Table 5. Correlation analysis of sensory terms used to describe cheese texture. Key for acronyms: Hand firmness (hfm), hand springiness (hsp), hand rate of recovery (hrc), first-bite firmness (ffm), first-bite fracturability (ffr), chewdown degree of breakdown (cbr), chewdown cohesiveness (cco), chewdown adhesiveness (cad), chewdown smoothness (csm), residual smoothness (rsm).

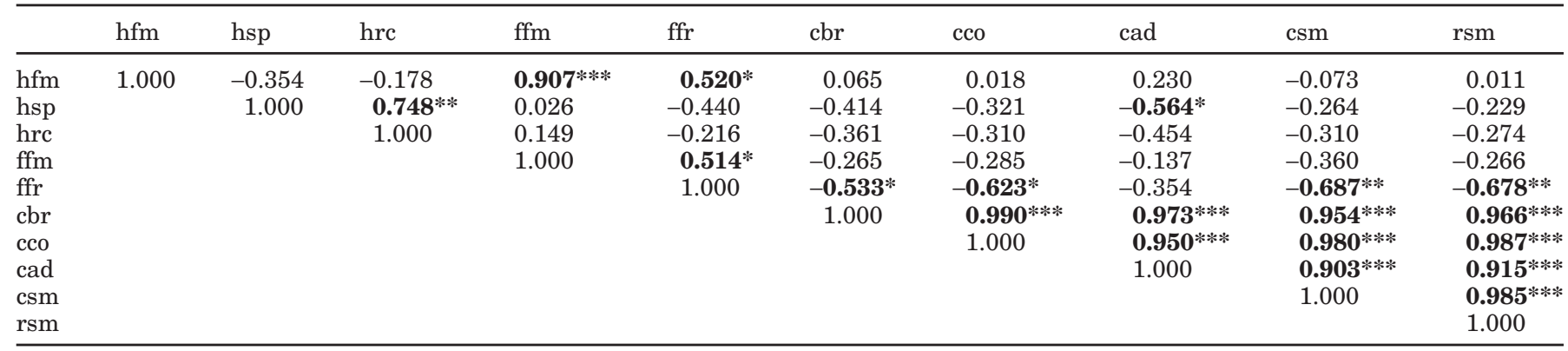

*Significant correlation at $P \leq 0.05$.

**Significant correlation at $P \leq 0.005$.

*** Significant correlation at $P \leq 0.0001$.

terms. It was noted that no instrumental terms were included in this grouping.

Principal component one accounted for $41.9 \%$ of the total variation in the samples and was able to differentiate the cheeses by variety. It was positively driven by the torsional parameters $\left(\mathrm{G}_{\mathrm{f}}\right)$, the small strain parameters $\left(G^{*}\right.$ and $\left.G^{\prime}\right)$, and sensory firmness. Process cheese had a much higher $\mathrm{G}_{\mathrm{f}}$ value than the other cheeses (Figure 4). This was expected, as this process cheese was a very dense, hard cheese when compared with the other cheeses. Likewise, Monterey Jack was slightly firmer than the Mozzarella cheese, char-

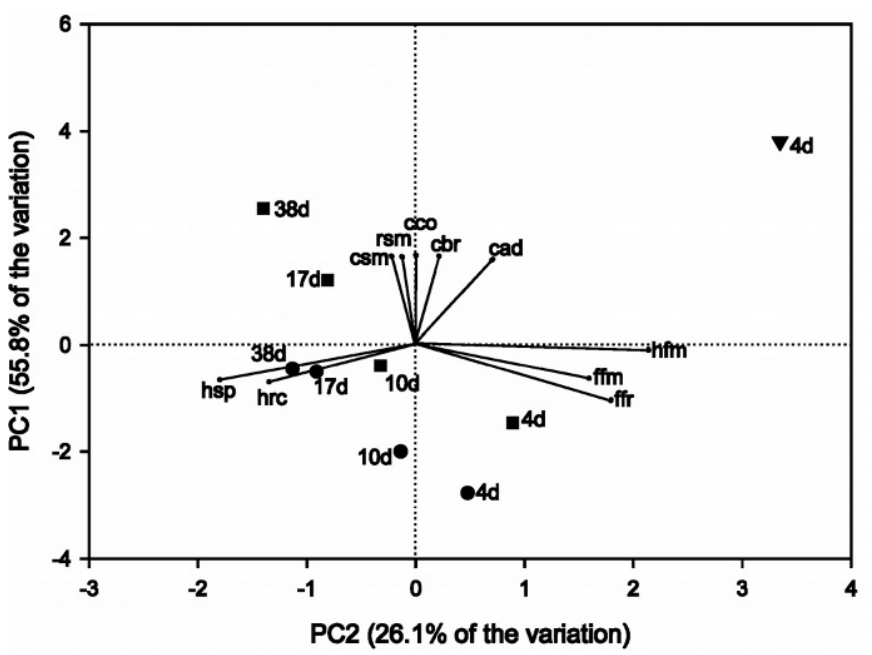

Figure 7. Principal component analysis biplot of sensory parameters used to differentiate Mozzarella (৩), Monterey Jack (ם), and process $(\boldsymbol{\nabla})$ cheeses by age (indicated by numbers beside symbol). Key for sensory parameters: Hand firmness (hfm), hand springiness (hsp), hand rate of recovery (hrc), first-bite firmness (ffm), first-bite fracturability (ffr), chewdown degree of breakdown (cbr), chewdown cohesiveness (cco), chewdown adhesiveness (cad), chewdown smoothness (csm), and residual smoothness (rsm). acteristics that could cause differentiation by the PC1 parameters. Instrumental terms $\left(\mathrm{J}_{\mathrm{mx}}\right.$ and $\left.\lambda_{\text {ret }}\right)$ and sensory terms (hrc and hsp) loaded negatively on PC1. The Mozzarella was the most pliant of the cheeses.

Principal component two, accounting for $29.2 \%$ of the total sample variation, ordered the cheeses chronologically. It represented the chewdown and residual sensory characterization as well as the perceived fracture properties of the cheese (negative relationship). As the cheeses aged, they became more cohesive, smooth, and sticky when chewed, and they fractured less.

The natural cheeses were categorically separated by PC3 (12.4\% of the total variation, data not shown). Monterey Jack loaded higher on PC3 than the Mozzarella; sensory springiness and rate of recovery was highly positively related to PC3. Additionally, $\mathrm{J}_{0}$ and $G^{\prime \prime}$ loaded positively on PC3. Instantaneous compliance $\left(J_{0}\right)$ is the compliance at time zero; it is a measurement of the initial elastic response of the protein matrix when a force is applied. A high $\mathrm{J}_{0}$ would indicate that the sample initially deforms to a greater extent when a constant force is applied.

\section{CONCLUSIONS}

Mozzarella, Monterey Jack, and process cheese all had greater elastic components $\left(G^{\prime}\right)$ than viscous components $\left(G^{\prime \prime}\right)$, were highly frequency dependent, and had low maximum strains for linear viscoelastic regions, indicating viscoelastic, weak gels. Sensory characteristics were able to differentiate the cheese by variety and by age, while rheological terms only differentiated by variety. Three distinct groupings of terms were observed relating to the rigidity, resiliency, and chewdown perception of the cheeses. As the cheeses aged, they became less rigid and more resilient. They also 
Table 6. Correlation analysis of sensory and instrumental terms used to define cheese texture. Key for acronyms: Hand firmness (hfm), hand springiness (hsp), hand rate of recovery (hrc), first-bite firmness (ffm), first-bite fracturability (ffr), chewdown degree of breakdown (cbr), chewdown cohesiveness (cco), chewdown adhesiveness (cad), chewdown smoothness (csm), residual smoothness (rsm), complex modulus ( $\mathrm{G}^{*}$ ), storage modulus $\left(\mathrm{G}^{\prime}\right)$, loss modulus $\left(\mathrm{G}^{\prime \prime}\right)$, phase angle $(\delta)$, fracture modulus $\left(\mathrm{G}_{\mathrm{f}}\right)$, instantaneous compliance $\left(\mathrm{J}_{\mathrm{o}}\right)$, maximum compliance $\left(\mathrm{J}_{\mathrm{mx}}\right)$, retardation time $\left(\lambda_{\text {ret }}\right)$, percent creep recovery (crp).

\begin{tabular}{|c|c|c|c|c|c|c|c|c|c|}
\hline & $\mathrm{G}^{*}$ & $\mathrm{G}^{\prime}$ & $\mathrm{G}^{\prime \prime}$ & $\delta$ & $\mathrm{G}_{\mathrm{f}}$ & $\mathrm{J}_{0}$ & $\mathrm{~J}_{\mathrm{mx}}$ & $\lambda_{\text {ret }}$ & crp \\
\hline $\mathrm{hfm}$ & $0.619 *$ & $0.623 *$ & 0.382 & $-0.823^{* * * *}$ & $0.660 * *$ & 0.005 & $-0.921^{* * * *}$ & $-0.638^{* *}$ & $0.802 * *$ \\
\hline hsp & -0.301 & -0.296 & 0.072 & 0.465 & $-0.832^{* * * *}$ & 0.400 & 0.298 & 0.534* & $-0.576 *$ \\
\hline hrc & -0.268 & -0.270 & 0.051 & 0.435 & $-0.575^{*}$ & 0.206 & 0.240 & 0.365 & -0.381 \\
\hline $\mathrm{ffm}$ & 0.499* & 0.504* & 0.403 & $-0.671^{* *}$ & 0.324 & 0.052 & $-0.823 * * *$ & -0.468 & 0.581* \\
\hline ffr & 0.169 & 0.165 & 0.021 & -0.402 & 0.417 & $-0.609 *$ & -0.418 & -0.449 & 0.350 \\
\hline cbr & 0.197 & 0.196 & 0.032 & -0.137 & $0.478 *$ & 0.405 & -0.120 & -0.153 & 0.364 \\
\hline cco & 0.217 & 0.217 & 0.075 & -0.1 & 0.391 & 0.459 & 0.000 & -0.124 & 0.303 \\
\hline cad & 0.341 & 0.340 & 0.112 & -0.315 & $\mathbf{0 . 6 4 6}^{* *}$ & 0.300 & -0.268 & -0.320 & $0.503^{*}$ \\
\hline $\operatorname{csm}$ & 0.237 & 0.239 & 0.099 & -0.109 & 0.324 & 0.419 & -0.024 & -0.087 & 0.228 \\
\hline rsm & 0.244 & 0.246 & 0.134 & -0.119 & 0.345 & $0.479^{*}$ & -0.080 & -0.090 & 0.269 \\
\hline
\end{tabular}

*Significant correlation at $P \leq 0.05$.

** Significant correlation at $P \leq 0.005$.

****Significant correlation at $P \leq 0.0001$.

increased in all chewdown characteristics. These groupings also showed the relationships between rheological properties and certain sensory perceptions. The combination of fracture and creep testing determines five rheological properties that correlate with eight of 10 sensory terms. The chewdown characteristics were the least correlated with rheological properties. This

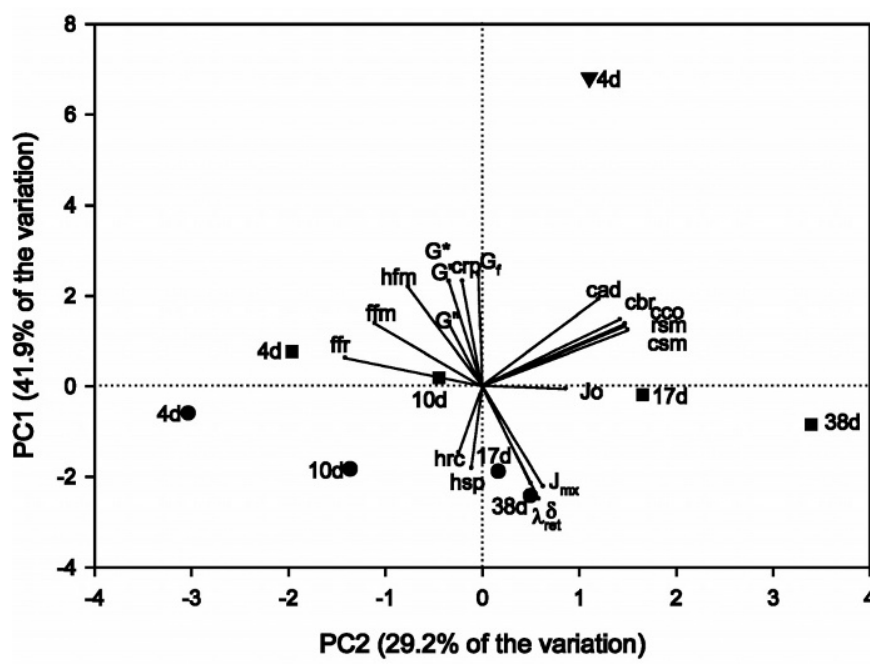

Figure 8. Principal component analysis biplot of sensory and instrumental parameters used to differentiate Mozzarella (•), Monterey Jack ( $\mathbf{\square})$, and process $(\boldsymbol{\nabla})$ cheeses by age (indicated by numbers beside symbol). Key for sensory parameters: Hand firmness (hfm), hand springiness (hsp), hand rate of recovery (hrc), first-bite firmness (ffm), first-bite fracturability (ffr), chewdown degree of breakdown (cbr), chewdown cohesiveness (cco), chewdown adhesiveness (cad), chewdown smoothness (csm), and residual smoothness (rsm). Key for instrumental parameters: Complex modulus $\left(\mathrm{G}^{*}\right)$, storage modulus $\left(G^{\prime}\right)$, loss modulus $\left(G^{\prime \prime}\right)$, phase angle $(\delta)$, fracture modulus $\left(G_{f}\right)$, initial compliance $\left(J_{0}\right)$, maximum compliance $\left(J_{m x}\right)$, percent creep recovery (crp), and retardation time $\left(\lambda_{\text {ret }}\right)$. study suggests that fundamental rheological properties can be used to understand cheese texture.

\section{ACKNOWLEDGMENTS}

Paper No. FSR-02-44 of the Journal Series of the Department of Food Science, North Carolina State University, Raleigh, NC 27695-7624. Support from the North Carolina Agricultural Research Service and the Southeast Dairy Foods Research Center and Dairy Management, Inc. are gratefully acknowledged. This is part of a collaborative project with Utah State University and the University of Wisconsin-Madison. We would like to thank the Department of Food Science at the University of Wisconsin for collecting and distributing cheeses. The technical support of Paige Luck and Den Truong is gratefully acknowledged.

\section{REFERENCES}

Adda, J., J. C. Gripon, and L. Vassal. 1982. The chemistry of flavour and texture generation in cheese. Food Chem. 9:115-129.

Antoniou, K. D., R. Petridis, S. Raphaelides, Z. Ben Omar, and R. Kesteloot. 2000. Texture assessment of French cheeses. J. Food Sci. 65:168-172.

Bogue, J. C., C. M. Delahunty, M. K. Henry, and J. M. Murray. 1999. Market-oriented methodologies to optimize consumer acceptability of Cheddar-type cheeses. Br. Food J. 101:301-316.

Bowland, E. L., and E. A. Foegeding. 1995. Effects of anions on thermal induced whey protein isolate gels. Food Hydrocoll. 9:47-56.

Casiraghi, E., M. Lucisano, and C. Pompei. 1989. Correlation among instrumental texture, sensory texture and chemical composition of five Italian cheeses. Ital. J. Food Sci. 1:53-63.

Chen, A. H., J. W. Larkin, C. J. Clark, and W. E. Irwin. 1979. Textural analysis of cheese. J. Dairy Sci. 62:901-907.

Christensen, C. M. 1984. Food texture perception. Adv. Food Res. 29:159-199.

de Jong, L. 1976. Protein breakdown in soft cheese and its relation to consistency: 1. Proteolysis and consistency of 'Noordhollandse Meshanger' cheese. Neth. Milk Dairy J. 30:242-253. 
Diehl, K. C., D. D. Hamann, and J. K. Whitfield. 1979. Structural failure in selected raw fruits and vegetables. J. Texture Stud. 10:371-400.

Drake, M. A., P. D. Gerard, and G. V. Civille. 1999a. Ability of hand evaluation versus mouth evaluation to differentiate texture of cheese. J. Sens. Stud. 14:425-441.

Drake, M. A., P. D. Gerard, V. D. Truong, and C. R. Daubert. 1999b. Relationship between instrumental and sensory measurements of cheese texture. J. Texture Stud. 30:451-476.

Guinard, J. X., and R. Mazzucchelli. 1996. The sensory perception of texture and mouthfeel. Trends Food Sci. Technol. 7:213-219.

Gwartney, E. A., E. A. Foegeding, and D. K. Larick. 2002. The texture of commercial full-fat and reduced-fat cheese. J. Food Sci. 67:812-816.

Hamann, D. D. 1983. Structural failure in solid foods. Pages 351383 in Physical Properties of Foods. M. Peleg and E. B. Bagley, ed. AVI Publishing Company, Inc., Westport, CT.

Kavanagh, G. M., and S. B. Ross-Murphy. 1998. Rheological characterization of polymer gels. Prog. Polym. Sci. 23:533-562.

Kindstedt, P. S., L. J. Kiely, and J. A. Gilmore. 1992. Variation in composition and functional properties within brine-salted mozzarella cheese. J. Dairy Sci. 75:2913-2912.

Konstance, R. P., and V.H. Holsinger. 1992. Development of rheological test methods for cheese. Food Technol. 46:105-109.

Lawrence, R. C., L. K. Creamer, and J. Gilles. 1987. Cheese ripening technology-texture development during cheese ripening. J. Dairy Sci. 70:1748-1760.

Lee, C. H., E. M. Imoto, and C. Rha. 1978. Evaluation of cheese texture. J. Food Sci. 43:1600-1605.

Ma, L., M. A. Drake, G. V. Barbosa Canovas, and B. G. Swanson. 1996. Viscoelastic properties of reduced-fat and full-fat cheddar cheeses. J. Food Sci. 61:821-823.

McEwan, J. A., J. D. Moore, and J. S. Colwill. 1989. The sensory characteristics of Cheddar cheese and their relationship with acceptability. J. Soc. Dairy Technol. 42:112-117.

McMahon, D. J., R. J. Fife, and C. J. Oberg. 1999. Water partitioning in mozzarella cheese and its relationship to cheese meltability. J. Dairy Sci. 82:1361-1369.
Munoz, A. M., and G. V. Civille. 1998. Universal, product and attribute specific scaling and the development of common lexicons in descriptive analysis. J. Sens. Stud. 13:57-75.

Murray, J. M., and C. M. Delahunty. 2000. Mapping consumer preference for the sensory and packaging attributes of Cheddar cheese. Food. Qual. Prefer. 11:419-435.

Nadai, A. 1937. Plastic behavior of metals in the strain-hardening range. Part I. J. Appl. Physics. 8:205-213.

Nolan, E. J., V. H. Holsinger, and J. J. Shieh. 1989. Dynamic rheological properties of natural and imitation Mozzarella cheese. J. Texture Stud. 20:179-189.

Sharma, F., and P. Sherman. 1973. Evaluation of some textural properties of foods with the Instron Universal Testing Machine. J. Texture Stud. 4:344-353.

Steffe, J. F. 1996. Rheological Methods in Food Process Engineering. Freeman Press, East Lansing, MI.

Szczesniak, A. S. 1963. Classification of textural characteristics. J. Food Sci. 28:385-389.

Taneya, S., T. Izutsu, T. Kimura, T. Shioya, W. Buchheim, P. S. Kindstedt, and D. G. Pechak. 1992. Structure and rheology of string cheese. Food Struct. 11:61-71.

Truong, V. D., and C. R. Daubert. 2001. Textural characterization of cheeses using vane rheometry and torsion analysis. J. Food Sci. 66:716-721.

Tunick, M. H. 2000. Rheology of dairy foods that gel, stretch, and fracture. J. Dairy Sci. 83:1892-1898.

Tunick, M. H., E. L. Malin, P. W. Smith, J. J. Shieh, B. C. Sullivan, K. L. Mackey, and V. H. Holsinger. 1993. Proteolysis and rheology of low-fat and full-fat Mozzarella cheeses prepared from homogenized milk. J. Dairy Sci. 76:3621-3628.

van Vliet, T., and P. Walstra. 1983. Rheology of curd and cheese. Neth. Milk Dairy J. 37:93-94.

Wendin, K., M. Langton, L. Caous, and C. Hall. 2000. Dynamic analyses of sensory and microstructural properties of cream cheese. Food Chem. 71:363-378.

Wilkinson, C., G. B. Dijksterhuis, and M. Minekus. 2000. From food structure to texture. Trends Food Sci. Technol. 11:442-450. 